- Its 2014-20 successor, Horizon 2020, will support the second phase. But the Horizon 2020 budget is likely to fall well short of the $€ 77$.6 billion proposed by the commission, and some observers fear that support earmarked for the flagships may be scaled back as a result.

Thousands of scientists across Europe worked intensively on developing the diverse project bids that were submitted to the competition - from computerized personal medicine to perceptive robots that respond to human needs. Some participants complain that the competition's goalposts seemed to shift during the selection process. At first, they claim, the commission stressed that winning projects would be chosen mainly for their scientific excellence. "But it became clear that impact for economic growth and for consumers was becoming more important - understandable in the economic climate," says Kinaret.

However, Wolfgang Boch, head of the commission's flagship unit, says that a panel of 25 experts from science and industry eventually chose the two winners on the basis of the published criteria, and that scientific excellence counted for $50 \%$ of the final ranking.

Even losers say they benefited from the competition. When the interim rankings were published last July, FuturICT was tipped to win. That project aims to model human activities and their impact on global political stability, the environment and financial markets. Its coordinator, Dirk Helbing, a physicist-turnedsociologist at the Swiss Federal Institute of Technology in Zurich, says he is disappointed, but that the interdisciplinary community the project created "will stay alive and active".

"We know that covert FuturICT-like projects are being started in other parts of the world," he says. "That makes it even more important to continue our open, transparent and participatory project." -

\title{
FUNDING
}

\section{UK research councils could face mergers}

\section{Wide-ranging review edges towards single funding pot.}

\section{BY GEOFF BRUMFIEL}

A government review that quietly began earlier this month could lead to major changes at the agencies charged with distributing much of the United Kingdom's scientific funding.

Possible changes to improve efficiency include bringing the roughly $£ 3$-billion (US\$4.7-billion) annual spend of all seven research councils into a single pot - potentially resulting in a body that would look rather like the US National Science Foundation (NSF). But observers fear that such a shakeup could bring years of chaos and disrupt the links between funders and the communities they serve.

At a minimum, says David Price, vice-provost for research at University College London, the recommendations "will have wide implications for the research sector". But he adds, "I don't think it's widely known that this is going on".

Conducted at the request of the powerful Cabinet Office, the review is designed to provide a robust challenge to the continuing need for the councils. It will also examine their current structure and may recommend reducing their number or consolidating them into a single grant-funding body.

The review, expected to be completed by the summer, is part of a broader examination of independent government bodies by Francis Maude, the chief cabinet minister. Last August, Maude announced that the government had already abolished 100 quasi-governmental organizations, and promised more cuts to

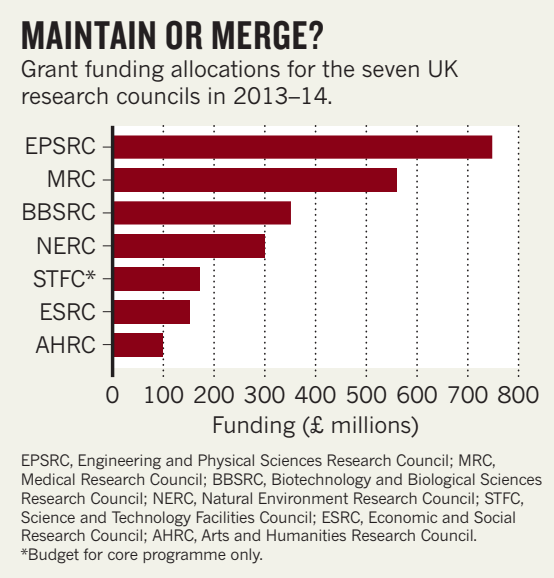

come. The research councils operate independently of their parent Department for Business Innovation and Skills (BIS), and as such, they are subject to the review. At its most extreme, the review committee could recommend that the councils are brought under the direct control of the BIS, which funds them, or be spun off as totally independent, charity-like bodies - although presumably still receiving government cash.

David Willetts, the government's minister for universities and science, doubts that such radical revisions are in store. "My view is that the model works pretty well, and I would be surprised if the review reached radical conclusions," he says. "But if there are lessons about For more on UK research council controversies, see: go.nature.com/fryeog
DNATURE.COM how [the councils] can raise their game, we'll look at it."

Past reviews of the councils have led to big changes, however. A 2001 review spawned an overarching body called Research Councils UK, which helps to coordinate the activities of the councils. A follow-up in 2004 led to the creation of a central system for the councils' human resources, information technology, finance, grants and recruitment.

Despite this recent consolidation, the councils remain largely independent bodies, with their own chief executives, advisory boards and budgets. "They represent very different functions and communities," says Luke Georghiou, vice-president for research and innovation at the University of Manchester, who participated in the 2001 review.

That could change with the latest review, which is being led by Ceri Smith, director of labour markets at the BIS, and an outsider to the academic community. Smith is believed to be considering various options, including consolidating several of the councils or appointing a single official to oversee the budgets of all of them (see 'Maintain or merge?'). Such changes might reduce administrative costs.

Pulling the research councils' budgets into a single pot might effectively create a single council similar to the NSF. That would be a mistake, says Georghiou. Unlike the NSF, which functions mainly to award and disburse grants, the councils have a diversity of obligations to the scientists they serve, including the running of institutes and facilities.

Research administrators also say that merging several councils could be especially unsettling at a time of tight budgets. Price serves on the board of the Science and Technology Facilities Council, which was formed out of a merger of two smaller councils in 2007. Budget cuts and administrative problems dogged the new council for years after the merger, he says. "The scars have just about healed now, but it took loads of time."

If yet more councils are fused, says Georghiou, "we could face three years of disruption at a time when we have to make maximum strategic use of what there is". 